\title{
Surgical repair of a tibial fracture in a Belgian Landrace pig
}

\author{
G. Vertenten, A. Martens, J. Declercq, S. Schauvliege, L. Weiland, F. Gasthuys \\ Department of Surgery and anaesthesiology of Domestic Animals, Faculty of Veterinary Medicine, \\ Merelbeke, Belgium
}

\begin{abstract}
Summary
This paper reports the surgical treatment of a tibial fracture in a castrated adult male Belgian Landrace pig of $180 \mathrm{~kg}$. The fracture was repaired using an intramedullary Steinmann pin, combined with cerclage wire and external transfixation. In contrast to other animal species, the fracture repair in the pig was hindered by the short and curved bones, the thick subcutaneous fat layer and the pronounced musculature. Postoperatively, the pig developed an osteomyelitis of the tibia due to pin tract contamination. Despite this complication, the fracture healed acceptably when all fixation material was removed two months after surgery. The infection resolved quickly and a satisfactory clinical result was obtained.
\end{abstract}

\section{Keywords}

Tibia, fracture, surgical treatment, osteomyelitis, pig

Vet Comp Orthop Traumatol 2006; 19: 180-3

\section{Introduction}

Swine reared for meat production with fractured long bones are destroyed or euthanatised because economic considerations preclude treatment. Moreover, pigs are legally deprived of a general anaesthesia according to Belgian law by the lack of anaesthetics with a Maximum Residue Level (M.R.L.) for pigs. Swine that will never enter the food chain, such as those with a high genetic or sentimental value, can be an exception. Fracture repair in pigs has rarely been described in literature. In 1966, Vaughan (1) reported the treatment of fractures in 12 pigs: eight of them recovered completely and could be used for breeding purposes. The aim of the present report of a tibial fracture in a Belgian Landrace pig is to describe one of the possibilities of fracture repair in swine.

\section{Case history}

A $180 \mathrm{~kg}$ castrated male pig was found with a fracture of the left tibia. The fractured leg was cast to mid-tibia by the local veterinarian and the pig was sent to the veterinary clinic at the University after sedation with 2 $\mathrm{mg} / \mathrm{kg}$ azaperone $\mathrm{e}^{\mathrm{a}}$ intramuscularly.

The clinical examination revealed an abnormal mobility of the left hind leg proximal to the cast. After cast removal, radiographs (planterodorsal and lateromedial views) were taken to confirm the preliminary diagnosis of a closed tibial fracture. A short oblique fracture was observed between the proximal and middle third of the tibia and fibula, with moderate fragmentation. The distal part of the tibia was displaced about $1 \mathrm{~cm}$ caudally (Fig. 1).

\section{Surgical procedure}

Sedation was still adequate to allow the induction of the anaesthesia. After induction with $10 \mathrm{mg} / \mathrm{kg}$, sodiumthiopental ${ }^{\mathrm{b}}$ using a catheter placed in an auricular vein and endotracheal intubation the anaesthesia was maintained with isoflurane ${ }^{c}$ in oxygen. Additionally, a bolus of $1 \mathrm{mg} / \mathrm{kg}$ lidocaine followed by a continuous infusion $(1.5 \mathrm{mg} /$ $\mathrm{kg} / \mathrm{h}$ lidocaine) was given.

The animal was restrained in dorsal recumbency and the affected leg was extended, as much as possible, by means of a hoist to fatigue the musculature in order to obtain a reduction of the fracture fragments. The leg was surgically prepared. A $10 \mathrm{~cm}$ skin incision was made on the medial aspect of the tibia to expose the fracture site. The hoist was dropped sufficiently to permit flexion of the stifle and tarsus. With the stifle and tarsus in a $90^{\circ}$ flexion, a retrograde placement of a $6 \mathrm{~mm}$ intramedullary Steinmann pin was performed. The length of the required pin was determined by using preoperative radiographs. A standard battery powered drill was used to drive the pin from the fracture site into the proximal fragment, exiting through an incision ca. $7 \mathrm{~cm}$ proximal to the tibial tuberosity. The pin was reintroduced with the sharp end pointing distally and the fracture was reduced and retention was obtained with a cerclage wire. Finally, the Steinmann pin was advanced in the distal fracture fragment using a hammer. The skin incisions were closed using simple interrupted sutures wit Polyglactin 910d.

External fixation was used to provide additional stability to the fracture. The leg was extended again and two $6 \mathrm{~mm}$ Steinmann pins were placed under fluoroscopic guid-

\footnotetext{
Pentotha ${ }^{\circledR}$, Abbott, Belgium.

IsoFlo ${ }^{\circledR}$, Abbott, UK.

d Vicryl ${ }^{\circledR}$, USP1, Ethicon, Belgium.
} 
ance in each fracture fragment through medial stab incisions. Holes were pre-drilled with a $5.5 \mathrm{~mm}$ drill bit from medial to lateral. The pins were placed perpendicular to the bone and, more or less, parallel to each other. The pin ends were trimmed to the correct length and were fixed on both sites with a $3.5 \mathrm{~cm}$ diameter polyethylene tube filled with methylmetacrylate ${ }^{\mathrm{e}}$. After application of an antibiotic spray ${ }^{\mathrm{f}}$ on the skin incision, the leg was protected with a bandage.

\section{Postoperative care}

Post-surgically, the pig received morphine $\mathrm{g}^{\mathrm{g}}$ $(0.17 \mathrm{mg} / \mathrm{kg}$ BW t.i.d. $)$ and flunixine meglumine $^{\mathrm{h}}(1.1 \mathrm{mg} / \mathrm{kg}$ BW s.i.d.) intramuscularly (IM) during 4 days. Sodiumceftiofur $(5.5 \mathrm{mg} / \mathrm{kg}$ s.i.d.) was administered IM during 10 days. The bandage was replaced every 4 days.

A radiographic follow-up was taken 14 days after the surgical intervention. The pig was sedated with $4 \mathrm{mg} / \mathrm{kg}$ ketamine ${ }^{\mathrm{j}}$ and 2 $\mathrm{mg} / \mathrm{kg}$ azaperone ${ }^{\mathrm{a}} \mathrm{IM}$, which allowed manipulation during radiography. There was a good apposition of the fracture fragments although a slight angle between the fragments could be remarked on the dorsoplantar view (Fig. 2A, B). As expected, radiographic signs of healing were not yet approved.

The bandages were changed at regular intervals and showed a normal healing of the wounds and apparent good stability of the fracture. Clinically, weight-bearing was relatively good the first few days after surgery, but decreased gradually afterwards. However, the pig was able to stand up and move around in its box. The animal was discharged from the clinic 18 days after surgery; it had lost $30 \mathrm{~kg}$ of bodyweight at that time.

Thirty-nine days postoperatively, an abscess was present at the level of the most proximal pin. It was drained by the referring

\footnotetext{
Demotec $^{\circledR} 90$, Germany.

Chlortetra spray ${ }^{\circledR}$, Eurovet, Belgium.

Stellorphinad $20^{\circledR}$, Stella, Belgium.

Emdofluxin $^{\circledR}$, Emdoka, Belgium.

Excenel $^{\circledR}$, Pfizer, Belgium.

Anesketin $^{\circledR}$, Eurovet, Belgium.
}

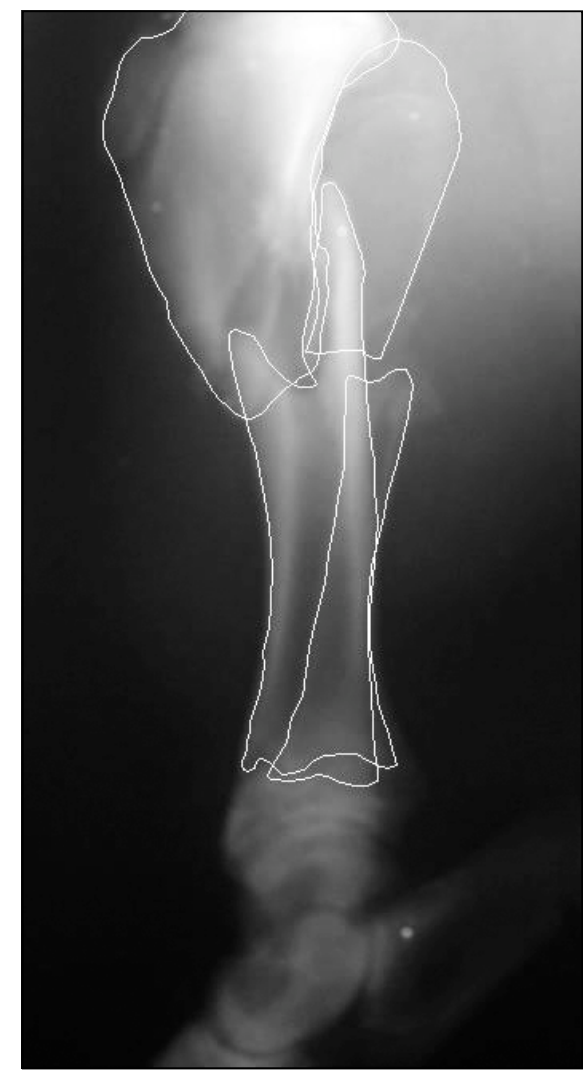

Fig. 1 Latero-medial view of the left tibia and fibula in a $180 \mathrm{~kg}$ castrated male Belgian Landrace pig: there is a slight oblique fracture between the proximal and middle third of the tibia and fibula with moderate fragmentation. The proximal part of the tibia is displaced by about $1 \mathrm{~cm}$ cranially.

*We apologise on behalf of the author for the poor quality of this radiograph. For this reason the bony structures have been outlined for improved visuality.
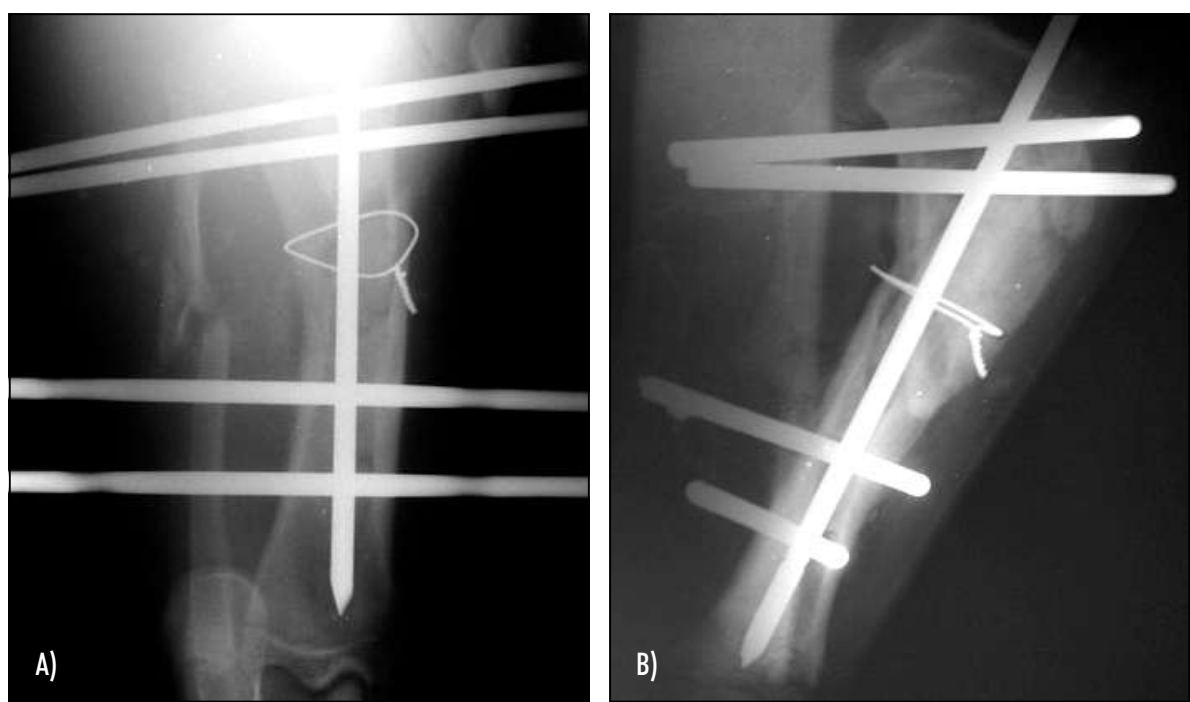

Fig. 2 A) Plantero-dorsal radiograph 14 days after surgery: a slight angle between the fragments of the fracture is visible. B) Latero-medial radiograph 14 days after surgery: apposition of the fracture is present. veterinarian and bacteriological culture revealed the presence of Proteus mirabilis and Streptococcus spp. Both bacteria were sensitive to Enrofloxacin and Amoxicillin with Clavulanic Acid. Therefore, the pig was treated with $4.9 \mathrm{mg} / \mathrm{kg}$ Amoxicillin and 0.7 $\mathrm{mg} / \mathrm{kg}$ Clavulanic Acid twice a day from day 49 after surgery. From then on, weight bearing on the affected limb gradually improved.

Eighty-two days after surgery the pig was readmitted to the clinic for removal of the external fixation. At that time it weighed $170 \mathrm{~kg}$ and still received oral Amoxicillin and Clavulanic Acidk twice a day. Although the tibia was diffusely swollen and a constant draining fistula was present on the medial site, the animal was weight-bearing well upon the affected leg. The lateral methylmetacrylate-filled tubing was broken at the level of the most proximal pin.

After premedication with $2 \mathrm{mg} / \mathrm{kg}$ azaperone ${ }^{\mathrm{a}}, 5 \mathrm{mg} / \mathrm{kg}$ ketamine $\mathrm{e}^{\mathrm{j}}$ and $0.1 \mathrm{mg} / \mathrm{kg}$ methadone $\mathrm{IM}$, general anaesthesia was induced with $5 \mathrm{mg} / \mathrm{kg}$ sodiumthiopental ${ }^{\mathrm{b}}$ intravenously. Following endotracheal entubation anaesthesia was maintained with isoflurane ${ }^{c}$ in oxygen.

The pig was restrained on its back and the external fixator was removed. All of the

\section{k Augmentin $^{\circledR}$, Aktuapharma, Belgium \\ Mephenon ${ }^{\circledR}$, Denolin, Belgium.}


pins were loose and a considerable amount of pus was draining from the pin tracts. The most proximal pin tract was in direct contact with the intramedullary pin. Radiographic views, taken under general anaesthesia, revealed an enormous periosteal reaction over the entire length of the tibia (Fig. 3). The fracture was considered to be healed, but the intramedullary pin had migrated distally and its sharp end was now very close to the tibiotarsal joint. Because of the risk of perforation of the tibiotarsal joint and the infection around the implants, it was decided to remove the intramedullary pin and the cerclage wire. The exact location of the proximal pin end and the cerclage wire were determined by ultrasonography. After scrubbing, disinfection and draping of the surgical field, an incision was made at the dorsomedial side of the proximal aspect of the tibia. The intramedullary pin was retrieved. Using a chisel and a hammer, the periostal reactions, that covered the proximal end of the intramedullary pin, were removed. A second incision was made on the medial aspect of the mid tibia to remove the cerclage wire and a small sequestered bone fragment. The pin tracts were rinsed abundantly with a $1 \%$ povidone-iodine solution ${ }^{\mathrm{m}}$ and were left to heal by second intention. The proximal and medial skin incisions were closed with Polyglactin $910^{\mathrm{d}}$, and the leg was bandaged.

The oral treatment with Amoxicillin and Clavulanic Acid was continued for 18 days (until 100 days post-operatively). After removal of the implants, the pig used the affected limb. Draining from the pin tracts ceased quickly and the pig was discharged from the clinic 3 days later. A final followup examination was performed 225 days after surgery. At that time the pig walked well and was not lame. Apart from some scars on the skin, the leg was totally recovered.

\section{Discussion}

Fracture repair in food producing animals is seldom performed. Nevertheless, tibial fractures have been repaired successfully in

\footnotetext{
m Poviderm Dermicum $^{\circledR}$, Ecuphar, Belgium.
}

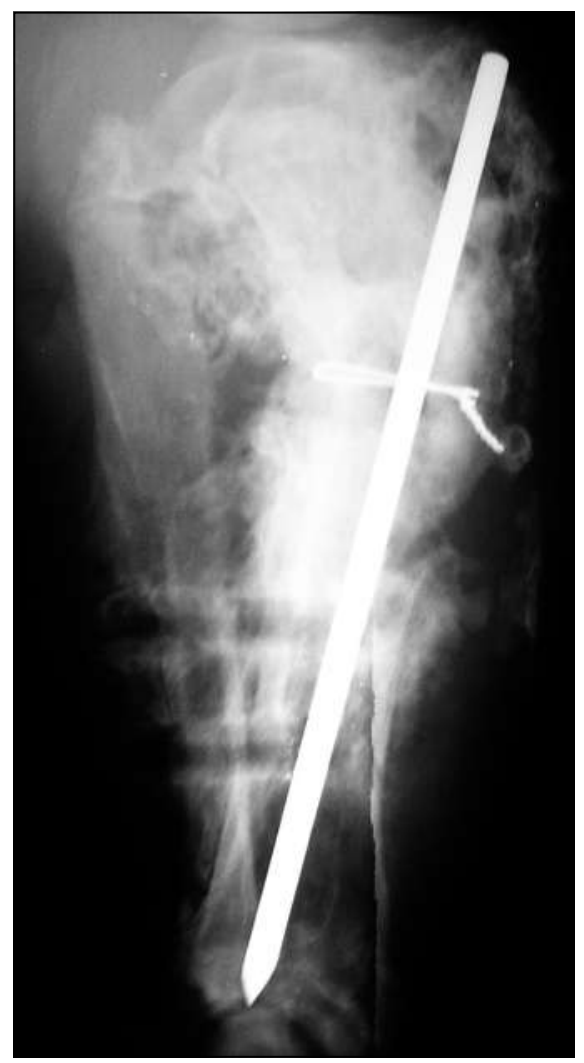

Fig. 3 Radiographs after removal of the transfixation pins at 82 days post-operatively: an important periostal reaction over the total length of the tibia has occured. The intramedullary pin migrated distally and the sharp end almost penetrates towards the tibiotarsal joint.

cattle by using bone plates, rush pins, Kuntscher nails, cross-pinning and transfixation pinning (2-8). Martens et al. (5) did not recommend surgical repair of tibial fractures with external transfixation in cattle weighing more than $400 \mathrm{~kg}$. Except for the use of a Thomas-splint, external transfixation is also not advised in fractures of the proximal epiphysis, comminuted fractures, intra-articular fractures and in the presence of proximal and distal fissure lines. Martens et al. (5) found that $44 \%$ of tibial fractures in cattle healed satisfactory with conservative treatment.

Under the current economic circumstances, fracture repair in pigs is rarely performed. Moreover, pigs are legally deprived of a general anaesthesia according to Belgian law because only the sedative azaperone ${ }^{a}$ has an M.R.L. for pigs. Under Belgian law, there are no drugs that can be legally used to induce general anaesthesia in swine that will ever enter the food chain (9). Animals of high genetic, or sentimental, value may be exempt from this rule.

The purpose of the lidocaine infusion is to decrease the isoflurane concentration. In dogs and horses, lidocaine infusions reduce the minimum alveolar concentration of isoflurane without subsequent effects on physiological and metabolic parameters $(10,11)$.

A few techniques are described for the repair of fractures in swine. Vaughan (1) described the successful treatment of four fractures of the tibia-fibula by single plating, two distal supracondylar fractures of the tibiafibula by casting, one femoral fracture by plating and one supracondylar humerus fracture by rest and limitation of mobility.

According to Vaughan (1), immobilisation with an external splint, or cast, is only possible in pigs when the injury involves the distal extremities or when the displacement is minimal. Because of their short and thick limbs, this type of immobilisation can not be used for other fractures in pigs. Intramedullary pinning as the sole method of fixation is also insufficient because of the thin cortices and wide medullary cavities in pigs. In a pig in Vaughan's (1), the diameter of the medullary cavity of the femur at mid-shaft was 32 $\mathrm{mm}$ which would require the insertion of a pin approximately $30 \mathrm{~mm}$ in diameter. At that time, mainly intramedullary Kuntscher nails were used, which need to be fixed very close to the bone cortex. It was not found to be practicable to introduce pins of such a size into the femur.

Because of the proximal localisation of the fracture in the present case, it was not possible to use conventional bone plates because the proximal bone fragment was too small to allow placement of at least three screws. The use of an 'interlocking nail' could be an option in this pig but an intramedullary nail and screws of the correct size were not available. Therefore, external fixation of the fracture was the most appropriate treatment for this case. The intramedullary pin and a cerclage wire were placed to obtain better retention of the reduced fracture. The intramedullary pin was able to provide additional stability to the fixation because the application of only two transfixation pins in each fracture fragment would probably not have been sufficiently stable. 
The reduction of the fracture was hindered by the short legs, the thick fat layer and the pronounced musculature of the pig. The hoist on the leg was frequently let up and down to assist in the manipulation of the fracture fragments. The use of a cerclage wire was indispensable to maintain fracture reduction until the intramedullary pin was placed. The retrograde placement of the intramedullary pin was also not easy, because of the thick subcutaneous fat layer around the proximal tibia and the stifle and the thick skin of the pig. The distance between the surface of the skin and the bone was approximately $8 \mathrm{~cm}$. Therefore, the initial stab incision was extended, and even then it was very difficult to pass the pin sufficiently distal. In dogs, intramedullary pins protruding too much above the tibia can hinder the movement of the stifle (12).

The use of external fixation in fracture repair can be complicated by external contamination through the pin tracts (3). This disadvantage is very important in swine, which are very difficult to keep clean. In cattle a local osteitis and osteomyelitis around the transfixation pins are often seen several weeks after pin placement. A treatment with only parenteral antibiotics can hardly control the occurring local osteomyelitis. To minimize the danger of infection from exposed or loose pins (3), the fixation device should be removed as soon as fracture healing is evident, Since the fracture in our case was fixed with a combination of an intramedullary nail, cerclage and external fixation, the infection, probably introduced via the transfixation pins, was spread all over the medullary cavity. The use of an appropriate antibiotic decreased lameness but the drainage via the pin tracts continued. Once the fixation was removed the drainage decreased very fast.

The case presented herein illustrates the possibility of repair of a tibial fracture in swine. It also reiterates the fact that healing of a fracture is possible despite the presence of osteomyelitis. Removal of the fixation device helps to resolve the infection.

\section{References}

1. Vaughan LC. The repair of fractures in pigs. Vet Rec 1966; 79: 2-8.

2. Aithal HP, Singh GR, Hoque M et al. The use of a circular external skeletal fixation device for the management of long bone osteotomies in large ruminants: an experimental study. J Vet Med A Physiol Pathol Clin Med 2004; 51: 284-93.

3. Hamilton GF, Tulleners EP. Transfixation pinning of proximal tibial fractures in calves. J Am Vet Med Assoc 1980; 176: 725-7.

4. Kumar R, Prasad B, Singh J et al. Cross-pinning technic for compound subarticular bovine fractures. Mod Vet Pract 1981; 62: 61-2.

5. Martens A, Steenhaut M, Gasthuys F et al. Conservative and surgical treatment of tibial fractures in cattle. Vet Rec 1998; 143: 12-6.
6. St-Jean G, Clem MC, DeBowes RM. Transfixation pinning and casting of tibial fractures in calves: Five cases (1985-1989). J Am Vet Med Assoc 1991; 198: 139-43.

7. Verschooten F, De Moor A, Desmet P et al. Surgical treatment of tibial fractures in cattle. Vet Rec 1972; 90: 24-9.

8. Vijaykumar DS, Singh APC, Nigam JM et al. Repair of bovine tibial fractures. Vet Med Small Anim Clin 1982; 77: 1109-14.

9. Gasthuys F. Anesthesie 'te velde' van varken en paard. Vlaams Diergeneeskundig Tijdschrift 2005; 74: 98-9.

10. Dzikiti TB, Hellebrekers LJ, van Dijk P. Effects of intravenous lidocaine on isoflurane concentration, physiological parameters, metabolic parameters and stress-related hormones in horses undergoing surgery. J Vet Med A Physiol Pathol Clin Med 2003; 50: 190-5.

11. Valverde A, Doherty TJ, Hernandez J et al. Effect of lidocaine on the minimum alveolar concentration of isoflurane in dogs. Vet Anaesth Analg 2004; 31: 264-71.

12. Brinker WO, Piermattei DL, Flo GL. Fractures of the tibia and fibula. In: Handbook of Small Animal Orthopedics \& Fracture Treatment, $2^{\text {nd }}$ ed., Brinker WO, Piermattei DL, Flo GL (eds.). W. B. Saunders Company, Philadelphia 1990; 140-55.

\section{Correspondence to:}

Geert Vertenten, DVM

Dept. of Surgery and Anaesthesiology of Domestic Animals

Faculty of Veterinary Medicine

Salisburylaan 133

9820 Merelbeke

Belgium

Phone: +329264 76 18, Fax: +329264 7794

E-mail: geert.vertenten@ugent.be 